\title{
Detection of tetracycline resistance determinant tetA gene and antimicrobial resistance pattern in Escherichia coli isolates recovered from healthy layer chickens
}

\author{
A. Balasubramaniam, M. Arthanari Eswaran, P. Suresh and K. Sukumar
}

\begin{abstract}
Department of Veterinary Microbiology, Veterinary College and Research Institute, Namakkal, Tamil Nadu, India. Corresponding author: A. Balasubramaniam, email: balasubramaniam72@gmail.com, MAE: drarthu@gmail.com, PS: vet suresh@yahoo.com, KS: drksugu@gmail.com

Received: 06-05-2014, Revised: 02-07-2014, Accepted: 12-07-2014, Published online: 02-09-2014
\end{abstract}

doi: 10.14202/vetworld.2014.635-638. How to cite this article: Balasubramaniam A, Arthanari Eswaran M, Suresh P, Sukumar K (2014) Detection of tetracycline resistance determinant tetA gene and antimicrobial resistance pattern in Escherichia coli isolates recovered from healthy layer chickens, Veterinary World 7(9):635-638.

\begin{abstract}
Aim: The aim was to study the occurrence of tetracycline resistance determinant tetA gene, and antibacterial resistance pattern in commensal Escherichia coli recovered from healthy non-clinical layer chickens.

Materials and Methods: Twenty-four cloacal swabs were obtained from 15 flocks in five different layer farms located at around Namakkal, which is a place of high-intensity layer chicken rearing in south India. Identification of E. coli was carried out by performing cultural and biochemical tests. Antimicrobial resistance test was carried out using disc diffusion method. The polymerase chain reaction employing tetAC forward and tetAC reverse primers were carried out to detect tetA gene conferring resistance to tetracycline.

Result: All the collected cloacal swabs yielded E. coli. Twenty-one isolates (88\%) were resistant to tetracycline antibiotic in disc diffusion method. All the isolates showed resistance to more than six antibiotics, which implied existence of multidrug resistant microbiota in intestine of poultry. Only seven (29\%) isolates showed the presence of tetA gene indicating the involvement of either other one or more efflux gene(s), namely tet $\mathrm{B}$, tet $\mathrm{C}$ and tet $\mathrm{D}$ or ribosomal protection encoded by tet $\mathrm{M}$, tet $\mathrm{O}$, tetQ and tet $\mathrm{S}$ genes than tetA gene.

Conclusion: Based on the presence of tetA gene among tetracycline-resistant bacteria in healthy non-clinical food-producing animals such as layer chickens, it can be significant in human medicine as tetA gene could easily be spread to other bacteria. This kind of phenomenon can be extrapolated in transfer of resistance for other antibacterial essential for treating bacterial infections in human. We conclude that preventing the spread of antimicrobial resistance through direct or indirect contact, consumed food/feed and through the environment is empirical in reduction of failures while treating bacterial infections.
\end{abstract}

Keywords: antibacterial resistance, Escherichia coli, tetA gene, tetracycline.

\section{I ntroduction}

The presence of antibiotic-resistant bacteria has reached epidemic proportions in recent years. The spread of antibiotic-resistant bacteria in the environment is dependent on the presence and transfer of resistance genes among microorganisms, and selection pressure to keep these genes in a population. One of the most controversial applications of antibiotics, however, is for growth promotion in livestock, and this application has raised concerns about its contribution to the presence of resistant bacteria in humans [1]. Tetracycline is a broad-spectrum antibiotic that inhibits bacterial protein synthesis by preventing aminoacyl-tRNA from binding to the bacterial ribosome [2]. Tetracycline is the drug commonly used along with anti-mycoplasmal drugs in commercial chickens to suppress the problems associated with Mycoplasma and other bacterial infections. Resistance to the antibiotic is conferred by one or more of the 36 currently described tet genes, which encode one of three mechanisms of resistance: An efflux pump,

Copyright: The authors. This article is an open access article licensed under the terms of the Creative Commons Attributin License (http:// creative commons.org/licenses/by/2.0) which permits unrestricted use, distribution and reproduction in any medium, provided the work is properly cited. a method of ribosomal protection, or direct enzymatic inactivation of the drug. Efflux mechanisms appear to be more abundant among Gram-negative microorganisms while ribosomal protection mechanisms are more common among Gram-positive organisms [3].

Gram-negative Escherichia coli is one of the resident microbiota (commensal) of the gut in animals. Several studies have examined tetracycline resistance among bacteria; most have employed clinically isolated bacteria [4] or populations specifically isolated for their ability to grow in the presence of tetracycline [5]. These studies do not give appraisal of the presence and types of tet genes that are present in commensal bacteria in the environment. Recent studies have shown that antimicrobial-resistant bacteria are present in different wild animals that have not been exposed to antibiotics [6,7]. Moreover, the resistance genes of bacteria from wild birds may result in increased numbers of resistant bacteria in livestock and humans [8].

Hence, the present study was planned to detect tetA gene and resistance against various antibiotics among $E$. coli obtained from healthy non-clinical layer chickens reared in five different locations in around Namakkal, South India. 


\section{Materials and Methods}

\section{Sample collection}

Twenty-four cloacal samples $(n=24)$ were collected from healthy non-clinical layers of different age group in five different commercial layer farms located in and around Namakkal, South India during September and November 2013. The detection of $E$. coli was performed by placing the swabs in buffered peptone water at $37^{\circ} \mathrm{C}$ for $24 \mathrm{~h}$, followed by aerobic culture on MacConkey agar and eosin-methylene blue agar at $37^{\circ} \mathrm{C}$ for $24 \mathrm{~h}$. The isolates were identified as per the method previously described [9].

\section{Antimicrobial susceptibility testing}

Resistance to tetracycline was tested by the disc diffusion by aerobic culture in Mueller Hinton agar using antibiotic discs (M/s Hi-Media, Mumbai, India). The discs employed were gentamicin, amikacin, ciprofloxacin, enrofloxacin, pefloxacin, norfloxacin, cephalexin, ampicillin, amoxicillin, co-trimoxazole and tetracycline. The susceptibility/resistant patterns of $E$. coli isolates to antibiotics were determined based on the size of the zones of inhibition and categorised as susceptible or resistant [10].

\section{Detection of tetracycline resistance gene tetA}

In E. coli isolates found to be resistant to tetracycline, polymerase chain reaction (PCR) was used to detect tetA gene encoding this resistance. Bacterial DNA was isolated from a 24-h culture on blood agar. Isolation of DNA was performed by lysis of bacterial cell suspension at $95.5^{\circ} \mathrm{C}$ for $10 \mathrm{~min}$, followed by centrifugation. The supernatant was used as template DNA. The tetA gene was amplified by PCR with forward primer tetAC F - 5'CGCYTATAT YGCCGAYATCAC-3' and reverse primer tetAC R - 5'CCRAAWKCGGCWAGCGA-3' which were designed based on regions showing high homology in E. coli genome with respect to relevant region [11] portion of the master mix (M/s Bio-Basic Inc., Canada) contained $1.5 \mathrm{U}$ of Taq polymerase, $20 \mathrm{nmol}$ of each deoxynucleoside triphosphate, $0.1 \mu \mathrm{L}$ of the template DNA, 100 pmol of each primer, and $10 \mu \mathrm{L}$ of the reaction buffer (100 mM Tris- $\mathrm{HCl}$ [pH 8.3], $500 \mathrm{mM} \mathrm{KCl}, 15 \mathrm{mM} \mathrm{MgCl} 2)$. PCR amplification included 30 thermal cycles of $60 \mathrm{~s}$ at $94^{\circ} \mathrm{C}, 45 \mathrm{~s}$ at $55^{\circ} \mathrm{C}$, and $90 \mathrm{~s}$ at $72^{\circ} \mathrm{C}$ with an additional extension of $300 \mathrm{~s}$ at $72^{\circ} \mathrm{C}$.

\section{Results}

E. coli was recovered from all the cloacal swabs collected from healthy non-clinical layer chickens. All the isolates produced characteristic reaction in biochemical tests (Table-1). Antibacterial resistant pattern against various antibiotics are summarized in Table-2. In antibacterial susceptibility testing, 21 isolates $(88 \%)$ were resistant to tetracycline antibiotic in disc diffusion method. Out of 24 isolates, 88\% were sensitive to cephalexin, 79\% to chloramphenicol, 58\% to ciprofloxacin, $58 \%$ to ampicillin, $54 \%$ to amoxicillin, $54 \%$ to enrofloxacin, 54\% to gentamicin, $43 \%$ norfloxacin, $29 \%$ to amikacin, $16 \%$ to co-timoxazole, $12 \%$ to pefloxacin and $12 \%$ to oxytetracycline.

All the tetracycline resistant $E$. coli isolates ( $n=21$ ) were subjected for PCR amplifying the efflux gene tetA (417 bp). Only seven (29\%) isolates showed the presence of tetA gene (Figure-1).

\section{Discussion}

The prevalence of $E$. coli in $88 \%$ of fecal samples of layer chickens in the present study was higher than the previous records [12,13]. We investigated the resistance pattern exhibited in vitro to various antibiotics by E. coli isolates recovered from healthy non-clinical layer chickens. Almost the vast majority E. coli isolated from chicken were resistant to tetracycline and sulpamethoxazole+trimethoprim. This might be explained by the fact that both are heavily used in the poultry industry in India and could be the result of inadvertent use [14]. This suggests that the extent of resistance to an antibiotic is associated with the extent of its use. The high antibiotic resistance rate of organisms isolated from animals is not a phenomenon unique to Indian poultry industry. The report found that $67 \%$ avian E. coli strains were resistant to sulpamethoxazole+trimethoprim that is $16 \%$ less than the finding in the present study and that resistance to the new fluoroquinolones was also increasing in

Table-1: Results of biochemical tests used for identification of Escherichia coli.

Gram-negative, small rod

Pink colonies on MacConkey agar

Colonies with green metallic sheen on eosin-methylene blue agar

Negative in citrate test

Negative in oxidase test

Positive in indole test

Positive in methyl red test

Negative in Voges-Proskauer test

Positive for catalase production

Positive for lactose fermentation

Positive for urea hydrolysis

Positive for nitrate Reduction

Positive for gelatin hydrolysis

Positive for case in hydrolysis

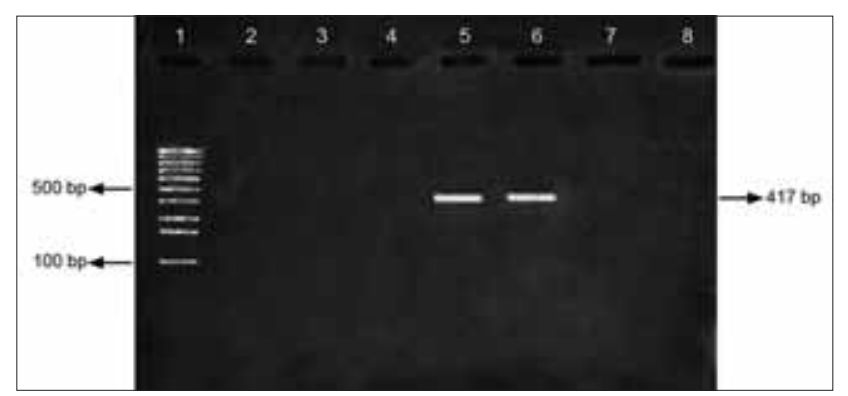

Figure-1: Agar gel elecrophoresis of polymerase chain reaction products with amplified tetA gene. Lane 1: $100 \mathrm{bp}$ DNA marker; Lane 5 and 6 showing amplicons of 417 bp and samples in other lanes are negative. 
Table-2: Antibiotic resistance pattern of avian E. coli isolates.

\begin{tabular}{lcc}
\hline $\begin{array}{l}\text { Antibiotic discs } \\
\text { (concentration in mg) }\end{array}$ & $\begin{array}{c}\text { No. of resistant } \\
\text { isolates }\end{array}$ & Percentage \\
\hline Gentamicin (10) & 11 & 46 \\
Amikacin (30) & 17 & 71 \\
Ciprofloxacin (30) & 10 & 42 \\
Enrofloxacin (30) & 11 & 46 \\
Pefloxacin (30) & 21 & 88 \\
Norfloxacin (10) & 14 & 58 \\
Cephalexin (30) & 3 & 13 \\
Ampicillin (30) & 10 & 42 \\
Amoxicillin (30) & 11 & 46 \\
Co-trimoxazole (25) & 20 & 83 \\
Tetracyline (30) & 21 & 88 \\
\hline
\end{tabular}

E. coli: Escherichia coli

Spain [15]. One report revealed multidrug resistance (MDR) in E. coli recovered from Irish cattle [16]. Daini and Adesemowo (2008) [17] found the resistance of E. coli clinical strains from Nigeria in 54 and $88 \%$ strains against gentamicin and tetracycline respectively, which is in agreement with the current finding. The high percentage of resistance to pefloxacin (88\%) and amikacin (71\%), which are rarely used in the poultry, is raising lot of questions as to why there is a high level of resistance to such antibiotics in natural non-clinical birds and how the bacteria acquired resistance against the antibacterials. If these antibiotics are to be used, it is used only for treating bacterial infections not amenable to other commonly applied antibiotics such as enrofloxacin, ciprofloxacin and gentamicin. MDR had been reported previously [13] where in all E. coli isolates exhibited resistance to more than six antibiotics that did not differ from the findings of the present work.

Only seven (29\%) E. coli isolates showed the presence of tetA gene despite percentage of tetracycline-resistant isolates was $88 \%$ in the present study. It can be assumed that tetracycline resistance in tetA negative isolates might be encoded by other genes such as tet $\mathrm{B}$, tet $\mathrm{C}$ and tet $\mathrm{D}$ or ribosomal protection encoded by tet $\mathrm{M}$, tet $\mathrm{O}$, tet $\mathrm{Q}$ and tet $\mathrm{S}$ genes than the gene monitored in this study. Not only did those animal hosts that presumably had continuous exposure to tetracycline have a higher percentage of tetracycline-resistant E. coli isolates, but also those isolates carried a greater diversity of resistance genes. Moreover, these isolates often had more than one tetracycline resistance determinant. This suggests that the human activity provides suitable environments that select for resistant strains and encourages the transfer of genetic information from unrelated bacterial species [12]. Koo and Woo (2011) [18] have reported that $98.3 \%$ of meat-borne E. coli containing at least one of the tetA to tetD genes was able to transfer tetracycline resistance to a tetracycline-susceptible recipient strain of E. coli. Interestingly, two isolates carried both tet $\mathrm{A}$ and tet $\mathrm{B}$, but only tetA was transferred to the recipient strain. It can be assumed that the tetA gene can be spread more easily in the environment than tetB. Antimicrobial resistance can spread to humans and animals via direct or indirect contact, consumed food/feed and through the environment. Therefore, it is important to analyze the epidemiology and mechanisms of emergence and spread of antimicrobial resistance [19].

\section{Conclusion}

Based on the findings, it can be stated that the presence of tetA gene among tetracycline-resistant bacteria in healthy non-clinical food-producing animals such as layer chickens assumes significance in human medicine as tetA gene could easily be spread to other bacteria and similar kind of spread can be extrapolated in transfer of resistance for other antibacterials essential for treating bacterial infections in human. We call for surveillance of more resistant conferring genes in resident microbiota among many food producing animals as it would reveal more than what emerged in the findings of the present study. We suggest prudent use of antibiotics for performance enhancement in food producing animals such as layer chickens and hygienic measures while handling animal food products to avoid crossing over of resistance genes from harmless bacteria to pathogenic bacteria.

\section{Authors' Contributions}

$\mathrm{AB}$ and $\mathrm{KS}$ have designed the plan of work and carried out the laboratory work. ME and PS have collected the relevant samples and have assisted in writing the manuscript. All the authors have read and approved the manuscript. AB revised the manuscript.

\section{Acknowledgments}

The authors are grateful to the Registrar, Tamil Nadu Veterinary and Animal Sciences University, Chennai for permitting us and funding the project to carry out the study and to the Dean, Veterinary College and Research Institute, Namakkal, Tamil Nadu, India for providing the facilities utilized in the work.

\section{Competing I nterests}

The authors declare that they have no competing interests.

\section{References}

1. Wegener, H.G., Aarestrup, F.M., Gerner-Smidt, P. and Bager, F. (1999) Transfer of antibiotic resistant bacteria from animals to man. Acta. Vet. Scand. Suppl., 92: 51-57.

2. Roberts, M.C. (1996) Tetracycline resistance determinants: Mechanisms of action, regulation of expression, genetic mobility, and distribution. FEMS Microbiol. Rev., 19(1): 1-24.

3. Chopra, I. and Roberts, M. (2001) Tetracycline antibiotics: Mode of action, applications, molecular biology, and epidemiology of bacterial resistance. Microbiol. Mol. Biol. Rev., 65(2): 232-260.

4. Arzese, A.R., Tomasetig L. and Botta, G.A. (2000) Detection of tetQ and ermF antibiotic resistance genes in Prevotella and Porphyromonas isolates from clinical specimens and resident microbiota of humans. J. Antimicrob. Chemother., 45(5): 577-582. 
5. Blake, D.P., Humphry, R.W., Scott, K.P., Hillman, K., Fenlon, D.R. and Low, J.C. (2003) Influence of tetracycline exposure on tetracycline resistance and the carriage of tetracycline resistance genes within commensal Escherichia coli populations. J. Appl. Microbiol., 94(6): 1087-1097.

6. Marinho, C., Silva, N., Pombo, S., Santos, T., Montero, R., Gonçalves, A., Micael, J., Rodrigues, P., Costa, A.C., Igrejas, G., and Poeta, P. (2013) Echinoderms from Azores islands: An unexpected source of antibiotic resistant Enterococcus spp. and Escherichia coli isolates. Mar. Pollut. Bull., 69(1-2): 122-127.

7. Poirel L., Potron A., De La Cuesta C., Cleary T., Nordmann, P. and Munoz-Price L.S. (2012) Wild coastline birds as reservoirs of broad-spectrum-beta-lactamase-producing Enterobacteriaceae in Miami Beach, Florida. Antimicrob. Agents Chemother., 56(5): 2756-2758.

8. Kitadai, N., Obi, T., Yamashita, S., Murase, T. and Takase, K. (2012) Antimicrobial susceptibility of Escherichia coli isolated from feces of wild cranes migrating to Kagoshima, Japan. J. Vet. Med. Sci., 74(3): 395-397.

9. Barrow, G.A. and Faltham, R.K.A. (1993) Cowan and Steel's Manual for Identification of Medical Bacteria. $3^{\text {rd }}$ ed. Cambridge University Press, London.

10. Bauer, A.W., Kirby, W.M.M., Sherris, J.C. and Turck, M. (1966). Antibiotic susceptibility testing by a standardized single disk method. Amer. J. Clin. Pathol., 45(4): 493-496.

11. Furushita, M., Shiba, T., Maeda, T., Yahata, M., Kaneoka, A., Takashi, Y., Torii, K., Hasegawa, T., and Ohita, M. (2003) Similarity of tetracycline resistance genes isolated from fish farm bacteria to those from clinical isolates. Appl. Environ. Microbiol., 69(9): 5336-5342.

12. Rahman, M., Rahman, B.M. and Rahman, B. (2008)
Antibiogram and plasmid profile analysis of isolated Escherichia coli from broiler and layer. Res. J. Microbiol., 3: 82-90.

13. Muhammad A.A., Hassan, S.M.R., Alam, S. and Shirin, M. (2009) Antibiotic resistance of Escherichia coli isolated from poultry and poultry environment of Bangladesh. American J. Environ. Sci., 5(1): 47-52.

14. Allan, B.J., Van-den-Hurk, W. and Potter, A.A. (1993) Characterization of Escherichia coli isolated from cases of avian colibacillosis. Can. J. Vet. Res., 57(3): 146-151.

15. Blanco, J.E., Blanco, M., Mora, A. and Blanco, J. (1997) Prevalence of bacterial resistance to quinolones and other antimicrobials among avian Escherichia coli strains isolated from septicemic and healthy chickens in Spain. J. Clin. Microbiol., 35(8): 2184-2185.

16. Karczmarczyk, M., Walsh, C., Slowey R., Leonard N., and Fanning, S. (2011) Molecular characterization of multidrug-resistant Escherichia coli isolates from Irish cattle farms. Appl. Environ. Microbiol., 77(20): 7121-7.

17. Daini, O.A. and Adesemowo, A. (2008) Antimicrobial susceptibility pattern and R plasmids of clinical strains of Escherichia coli. Aus. J. Basic Appli. Sci., 2: 397-400.

18. Koo, H. and Woo, G. (2011) Distribution and transferability of tetracycline resistance determinants in Escherichia coli isolated from meat and meat products. Int. J Food Microbiol., 145(2-3): 407-413.

19. Santos, T., Silva, N., Igrejas, G., Rodrigues, P., Micael, J., Rodrigues, T., Resendes, R., Gonçalves, A., Marinho, C., Gonçalves, D., Cunha, R. and Poeta, P. (2013) Dissemination of antibiotic resistant Enterococcus spp. and Escherichia coli from wild birds of Azores Archipelago. Anaerobe., 24: 25-31. 